Proc. Indian Acad. Sci., Vol. C2, Part 4, December 1979, pp. 451-471. (C) Printed in India.

\title{
A study on bullock carts. Part 2. Experimental study of forces in a bullock cart
}

\author{
M R RAGHAVAN and D L PRASANNA RAO \\ Department of Mechanical Engineering, Indian Institute of Science, Bangalore 560012
}

MS received 20 October 1979

\begin{abstract}
A strain gauge load cell with separate bridges for measurement of the pull and the bending moment in the plane containing the net neck load and pull was developed and fixed in the longitudinal member of an experimental cart. A cart fitted first with pneumatic wheels and then with steel-rimmed wooden wheels was tested on three terrains - tar road, mud road and grassy terrain. Pull vs time and moment vs time records were obtained in each test and analysed.

It is found that the bullocks pull the cart rather discontinuously at the low. velocities at which these carts normally operate. On the tar road and the grassy terrain, the mean static coefficient of friction is significantly higher for the cart with steelrimmed wooden wheels. The dynamic frictional resistance of the terrain for the cart with steel-rimmed wooden wheels is lower than for the cart with pneumatic wheels so long as the wheels do not dig or sink into the terrain. The fluctuation in the neck load is lower in the cart fitted with pneumatic wheels. Also, the ground-induced lowamplitude high-frequency vibratory load content in the neck load is lower in the cart with pneumatic wheels.
\end{abstract}

Keywords. Bullock cart; experimental'cart; measurement; strain gauge load cell; calibration; frictional resistance.

\section{Introduction}

The net load capacity of conventional and two-wheel pneumatic (Dunlop ADV tyres) tyre carts are claimed to be about 1 tonne and 2.5 tonnes respectively (Anon 1977). From steady static tests some comparative data have been obtained on the effective rolling friction $\mu$ (combined ground friction and bearing friction) offered in cases of steel-rimmed wheels and pneumatic tyres on a few typical terrains. The data given in table 1 (Marks 1951) show that $\mu$ for pneumatic tyres on concrete road is slightly more than for steel-rimmed wheels. On other terrains, $\mu$ for pneumatic tyres is only 15 to $25 \%$ lower. This implies that the draw-bar pull in carts fitted with pneumatic tyres is about 1.6 to 1.75 that of conventional carts if it has to carry 2.5 times the net load carried by conventional carts. No data are available on the effect of carrying such heavier loads on the necks of the bullocks and their life.

In a series of investigations conducted more than three decades ago (Vagh 1944-51) several designs for the steel-rimmed wooden bullock-cart wheel were tested in a cart pulled manually by several persons. A special spring-dynamometer involving the use of a third wheel in front was used to record on a drum recorder the variation of draw-bar pull during the test. The spring-dynamometer-cum-recorder is perhaps

$A$ list of symbols appears at the end of the paper. 
Table 1. Data on $\mu$ for pneumatic and steel-rimmed wheols (Marks 1951)

\begin{tabular}{|c|c|c|c|c|c|}
\hline \multirow{2}{*}{ Type of Wheel } & \multirow{2}{*}{$\underset{\text { kgf }}{\text { Load }}$} & \multicolumn{4}{|c|}{ Surface } \\
\hline & & Concrete & $\begin{array}{l}\text { Blue grass } \\
\text { sod }\end{array}$ & $\begin{array}{l}\text { Tilled } \\
\text { loam }\end{array}$ & $\begin{array}{l}\text { Loose } \\
\text { sand }\end{array}$ \\
\hline $\begin{array}{l}\text { Wheel with steel } \\
\text { tyres (diameter } 60 \text { to } \\
120 \mathrm{~cm} \text {; width: } 6 \cdot 3 \\
\text { to } 20 \mathrm{~cm} \text { ) }\end{array}$ & $\begin{array}{l}227- \\
682\end{array}$ & $\begin{array}{l}0.010- \\
0.034\end{array}$ & $\begin{array}{l}0.065- \\
0.094\end{array}$ & $\begin{array}{l}0.236 \\
0.468\end{array}$ & $\begin{array}{l}0.264- \\
0.504\end{array}$ \\
\hline $\begin{array}{l}\text { Pneumatic tyres } \\
\text { (4-18 to } 7 \cdot 5-36 ; 9-16 ; 4 \text { to } \\
6 \text { ply) (tyre pressure: } \\
\left.1 \cdot 1-2 \cdot 5 \mathrm{~kg} / \mathrm{cm}^{2}\right)\end{array}$ & $\begin{array}{l}227- \\
682\end{array}$ & $\begin{array}{l}0.017- \\
0.042\end{array}$ & $\begin{array}{l}0.050 \\
0.070\end{array}$ & $\begin{array}{l}0.185- \\
0.401\end{array}$ & $\begin{array}{l}0.177- \\
0.460\end{array}$ \\
\hline
\end{tabular}

unsuitable for use with bullocks providing the tractive effort. These tests were conducted on concrete, water-bound (WB) Macadam and earth roads. From drawbar pull and minimum damage to road considerations, it was claimed that the steelrimmed wooden wheels (conventional design) are satisfactory provided the tyre width is increased from $5 \mathrm{~cm}$ to $7.5 \mathrm{~cm}$.

However, no detailed analysis has been reported in the literature on $\mu$ and the dynamic effects on the pull and neck loads under actual operating conditions. Hence, in the present study, a two-wheel cart was fitted with a strain gauge load cell specially designed for this purpose. The instrumented cart provided independent records of pull and neck load under actual operating conditions. Details about this instrumented cart and analysis of the results of tests wherein this cart fitted first with pneumatic tyres and then with conventional steel-rimmed wheels was operated on various types of terrains, are presented here.

For an experimental study of the performance of a two-wheel bullock cart fitted with either steel-rimmed wooden wheels or pneumatic wheels and operating on various types of terrains, the forces exerted by the bullocks on the cart have to be measured under actual operating conditions. A load cell is required to measure these forces. An important requirement this load cell has to satisfy is that its introduction into the system should not significantly alter the characteristics of the bullock cart. The load cell and the associated instruments should faithfully record the dynamic variations of these forces i.e., the pull and the neck load, while the cart is in motion. A study of various measuring devices show that a strain gauge load cell fitted in the longitudinal member (figure 1) of the cart is well suited for this purpose.

\section{Strain gauge load cell}

A load cell located in the longitudinal member of the cart is subjected to the following forces and moments (figure 1)

$$
\begin{aligned}
& P=P_{1}+P_{2}, \\
& W_{R}=W_{R 1}+W_{R 2},
\end{aligned}
$$



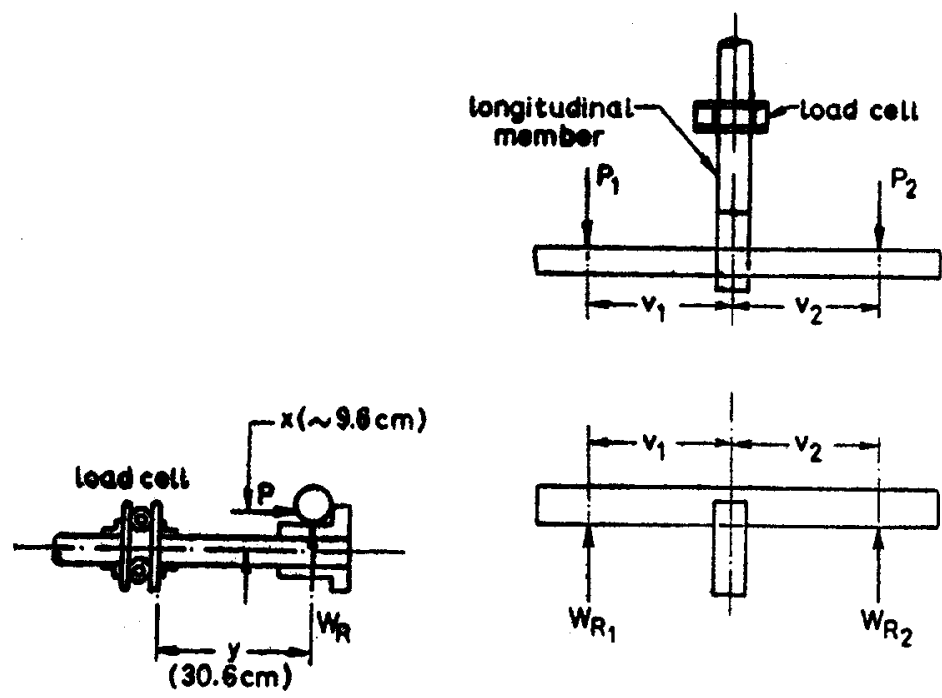

Figare 1. Forces on the yoke of the bullock cart

$$
\begin{aligned}
& M_{11}=W_{R} y-P x, \\
& M_{n n}=P_{1} v_{1}-P_{2} v_{2}, \\
& T=W_{R 1} v_{1}-W_{R 2} v_{2},
\end{aligned}
$$

where $P_{1}$ and $P_{2}$ are the pulls exerted by the two bullocks and $W_{R 1}$ and $W_{R 2}$ are the corresponding neck loads on the bullocks.

The load cell should satisfy the following important requirements:

(i) it should be capable of measuring at any instant both $P$ and $W_{R}$;

(ii) the output of the load cell corresponding to $P$ should be insensitive to the magnitude of the shear force $W_{R}$, the bending moments $M_{l l}$ and $M_{n n}$ and torque $T$;

(iii) the output of the load cell corresponding to the neck load $W_{R}$ could either indicate directly the neck load or give the neck load indirectly through the bending moment $M_{l l}$. In the present design it was found convenient to measure $M_{l l}$. The load cell output indicating this bending moment should be unaffected by the stresses in the load cell due to the axial load $P$, shear force $W_{R}$, bending moment, $M_{n n}$ and torque $T$.

(iv) The stiffiness of the load cell in both longitudinal and transverse directions should preferably be greater than the stiffness of the longitudinal wooden member.

A strain-gauge load cell which satisfies all these requirements is shown in figures 2 and 3. In this load cell, four stainless steel octagonal rings each having $40 \mathrm{~mm}$ inside diameter and $3 \mathrm{~mm}$ minimum wall thickness, are sandwiched between two $15 \mathrm{~mm}$ thick mild steel plates. Bolts ( $8 \mathrm{~mm}$ diameter) and nuts are used to fix these rings to the 

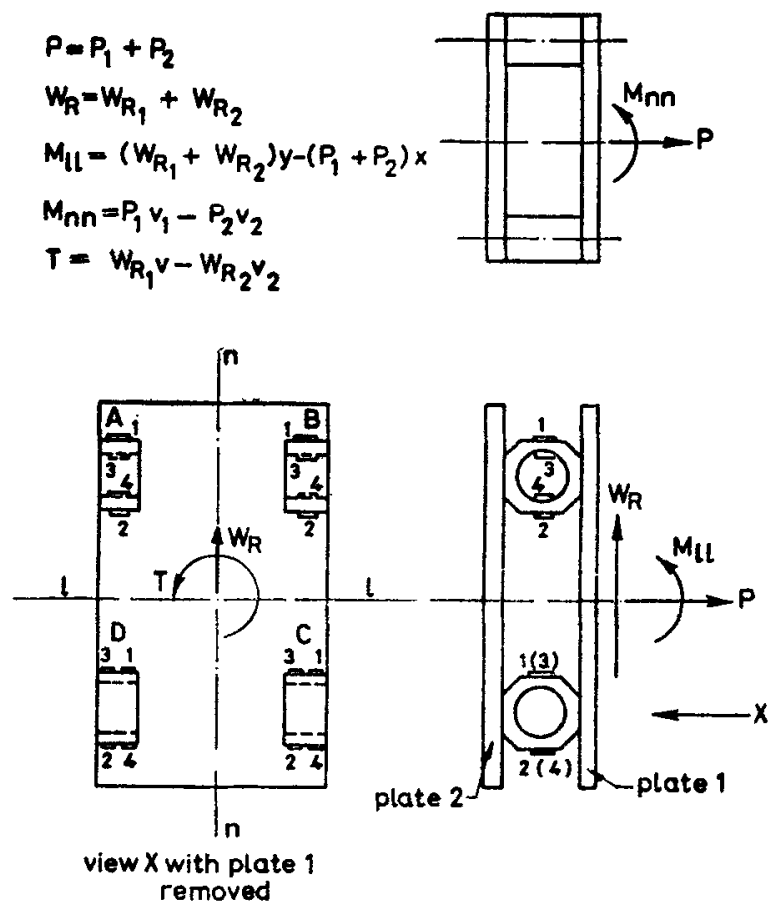

Figure 2. Forces and moments on the load cell

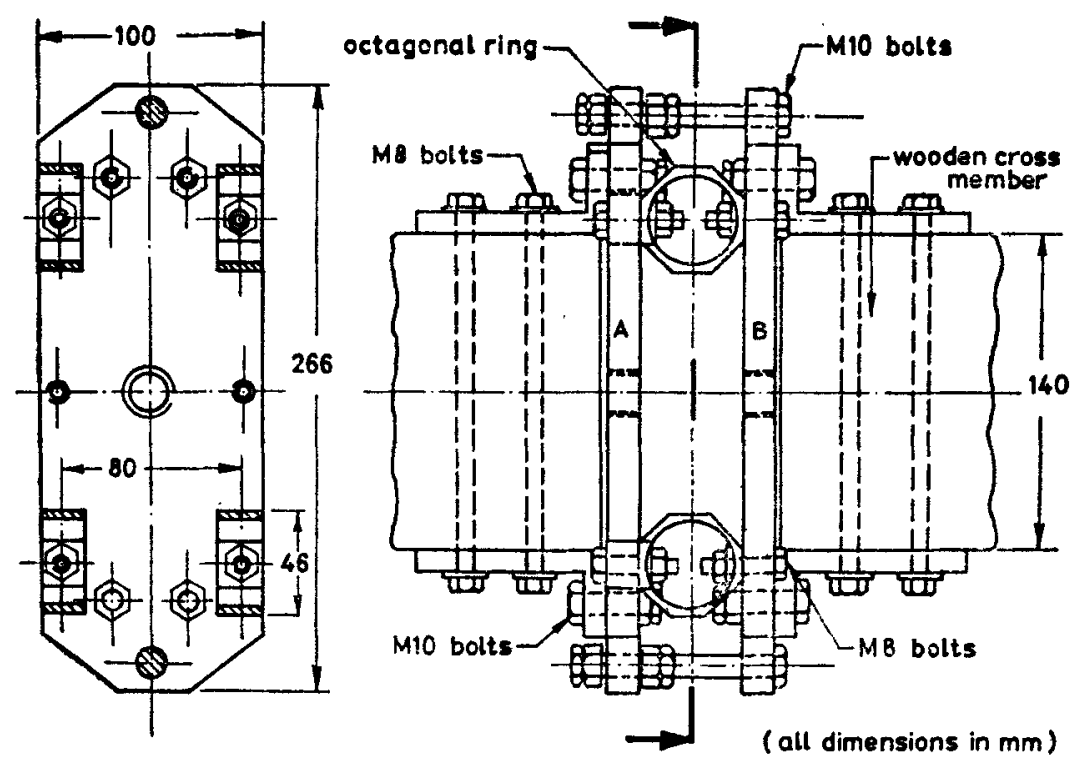

Figure 3. Load cell assembly 


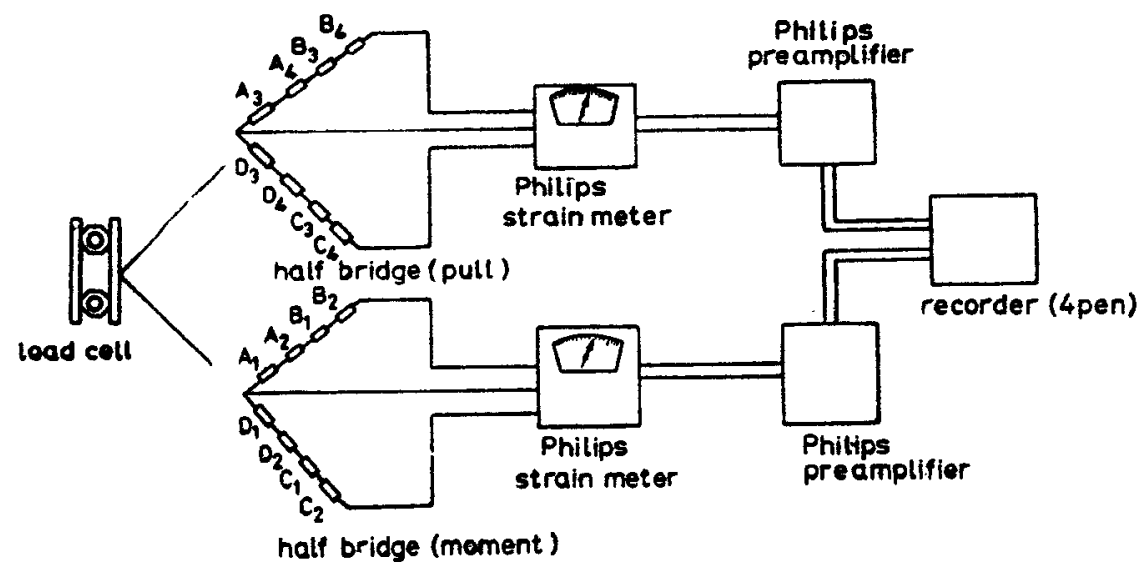

Figure 4. Load cell output recording system

steel plates. Sixteen $120 \Omega$ strain gauges (Satya gauge type SA-12-STCL, grid length $5 \mathrm{~mm}$ ) are fixed on these rings as shown in figure 2 . These strain gauges are connected as shown in figure 4 to form two half-bridges for measuring directly $\boldsymbol{P}$ and $M_{l l}$. The half bridges are connected to a Kelvin and Hughes four-pen recorder through Phillips strain meters and preamplifiers (figure 4). The excitation voltage (220 V 50 cycles $\mathrm{AC}$ ) for the strain-measuring system was obtained through a petrol enginegenerator set mounted on the platform of the cart (figure 5, plate 1). An automatic voltage regulator was used to obtain steady voltage supply. All measuring instruments and associated equipment were mounted on the platform of the cart (figure 5 , plate 1).

Some design details on the load cell are given in figure 3. As may be seen in this figure, stops are provided to prevent the overloading of the load cell. The longitudinal wooden member in the cart is cut at a station about $30 \mathrm{~cm}$ from the yoke end and the load cell is fixed between the cut pieces through angles, bolts and nuts (figure 3 ).

\section{Calibration of the load cell}

The four octagonal-faced rings with strain gauges fixed on them were individually tested in compression in an universal testing machine for checking the satisfactory performance of the strain gauges. The load cell was then assembled and tested in tension in the universal testing machine. After ensuring satisfactory performance of the load cell the stops were adjusted to limit the maximum axial load to $500 \mathrm{kgf}$ and bending moment to $30 \mathrm{kgfm}$. The load cell was then fixed as described earlier to the longitudinal member of the cart and instrumented. It was then calibrated for axial load and bending moment.

The set-up used for axial load calibration through dead weights is shown in figure 6 (an additional joint provided in the longitudinal wooden member between the load cell and the wooden platform facilitated this test). The calibration constant for axial load was found to be $1.03 \mu \mathrm{\epsilon} / \mathrm{kgf}$. The cross sensitivity i.e., the ratio of the outputs of the bending moment bridge and the axial load bridge, was less than $2 \%$.

Two arrangements shown in figure 7 were used for bending moment calibration through dead weights. In one set-up (figure 7a) vertical loads were applied on the yoke 


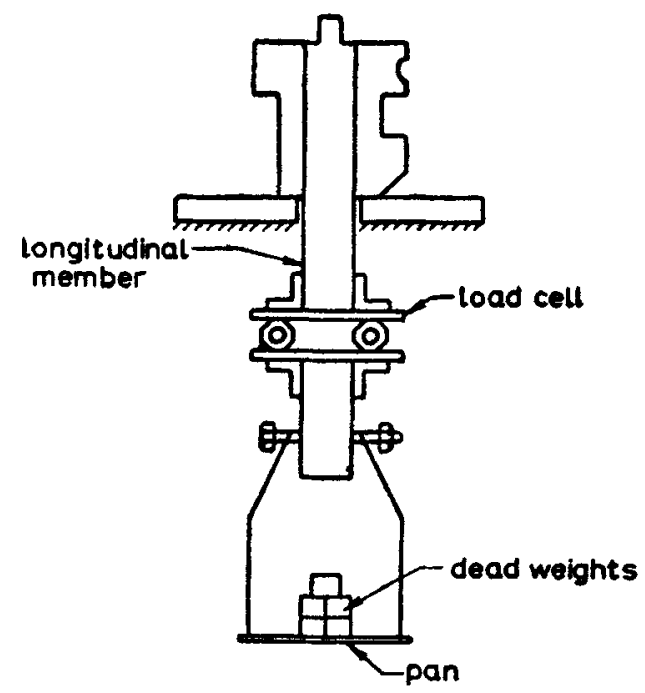

Figure 6. Set-up for axial load calibration using dead weights.

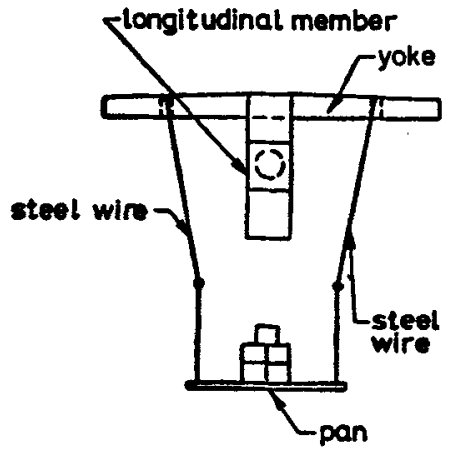

(a)

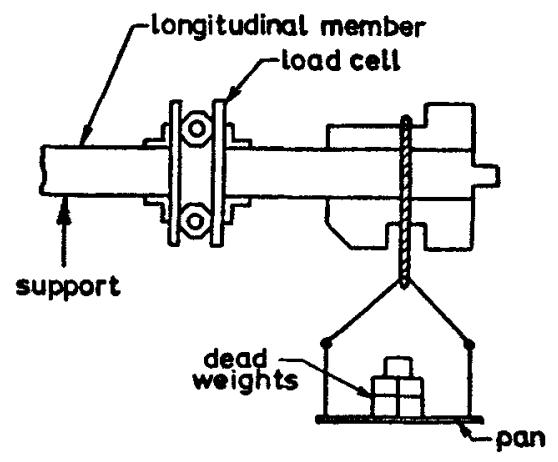

(b)

Figure 7. Arrangements for bending moment calibration with simulated load $W_{R}$.

at the locations where the yoke rests on the two bullocks. In the other set-up (figure $7 \mathrm{~b}$ ), a vertical load was applied directly to the longitudinal member at the section where the yoke transmits in the actual cart, load to the longitudinal member. Both tests gave the same calibration constant of $3.3 \mu \in$ per kgf vertical load in the yoke i.e., $9.3 \mathrm{kgcm}$ bending moment per $\mu \epsilon$.

During the actual test, a shunt resistance was used to calibrate the axial load measuring system in terms of pen deflection per unit micro strain on the strain meter. This used along with the calibration constant of the load cell in terms of microstrain per unit axial load i.e., $1.03 \mu \epsilon / \mathrm{kgf}$ gave the calibration constant for the axial load measuring system in terms of load per millimeter pen deflection; this calibration constant was about $29.5 \mathrm{kgf} / \mathrm{mm}$ deflection of the pen recorder.

In the case of bending moment measuring system, the calibration constant in terms of pen deflection per unit microstrain was found at the commencement of each test by applying a static lateral load on the yoke of the cart. This data used along with 
calibration constant from the earlie rcalibration test i.e., $3 \cdot 3 \mu \epsilon / \mathrm{kgf}$ vertical load gave the calibration constant of the bending moment measuring system in terms of $\mathrm{kgf}$ per $\mathrm{mm}$ pen deflection. About $10 \mathrm{kgf}$ vertical load on the yoke produces $1 \mathrm{~mm}$ deflection of the pen of the recorder.

From the measured values of the bending moment $M_{l l}$ and the pull $P$ the corresponding neck load can be determined through equation (1c). Thus

$$
W_{R}=\left(M_{u l} / y\right)+(P x / y)
$$

\section{Test conditions}

The experimental cart fitted alternately with conventional steel-rimmed wheels and pneumatic wheels were tested on three types of terrains located around the Internal Combustion Engineering building of the Indian Institute of Science, Bangalore. The specifications of the experimental cart and details about the pneumatic and wooden wheels are given in table 2 . The three types of terrains are:

(i) tar road: two strips hereafter termed as tar road 1 and tar road 2;

(ii) dry mud road: a stretch of road with a thin layer of mud over compacted stone jelly and sand;

(iii) unprepared grassy (green grass) terrain.

Table 2. Specification of the experimental cart

1. General:

Platform size: $218 \mathrm{~cm} \times 82.5 \mathrm{~cm}(86 \mathrm{in} . \times 32.5 \mathrm{in}$.)

Platform height from the ground: $106 \mathrm{~cm}(41.8 \mathrm{in}$.)

Distance between the wheel centre and the neck of the bullocks, $c=283 \mathrm{~cm}(111.5 \mathrm{in}$.)

Height of the neck of the bullocks from the ground $h=100 \mathrm{~cm}$ (40 in.)

Centre distance between the bullocks (necks): $107 \mathrm{~cm}$ (42 in.)

2. Steel-rimmed wooden wheels

Diameter $D_{w}: 150 \mathrm{~cm}(60 \mathrm{in}$.)

Width $: 5 \mathrm{~cm}(2 \mathrm{in}$.

Thickness of steel belt: $1.5 \mathrm{~cm}(0.6 \mathrm{in}$.)

No. of spokes: 12

Axle diameter: $3.2 \mathrm{~cm}$ ( 1.25 in.)

Weight of each wheel: $86.2 \mathrm{kgf}(190 \mathrm{lb}$.)

Centre distance between the wooden wheels on the cart: $126 \mathrm{~cm}(49.5 \mathrm{in}$.)

3. Pneumatic wheels

Specification: $S 75-6 \cdot 00-16,6$ ply rating

Type: New Deluxe Champion of $\mathrm{M} / \mathrm{s}$ Firestone

Outside diameter of inflated wheels: $70 \mathrm{~cm}(27.5 \mathrm{in}$.)

Tread width: $11 \mathrm{~cm}(4 \cdot 3 \mathrm{in}$.); Tread partially worn

Weight of pneumatic wheels with axle and tie rod assembly: $71 \cdot 2 \mathrm{kgf}(157 \mathrm{lb}$.)

Centre distance between the wheels: $128 \mathrm{~cm}(50.5 \mathrm{in}$.)

Tyre pressure: 1.4 and $2.1 \mathrm{kgf} / \mathrm{cm}^{2}$ (20 and $30 \mathrm{psig}$ ) 


\section{Test procedure}

Besides the strain measuring equipment and the engine-generator set, cast iron weights were placed in the cart in suitable positions to provide the required load on the cart. The static neck load on the two bullocks with the cart driver in position was in the range of 40 to $56 \mathrm{kgf}$.

At the commencement of each test, the platform of the experimental cart (without the bullocks) was made horizontal by supporting the longitudinal member at a point between the load cell and the platform so that there was virtually no load on the load cell. The engine-generator set was then started and the strain measuring bridges were activated and allowed to warm up. After balancing the bridges for capacitance and resistance unbalance, both the bridges were calibrated as described above. The support to the longitudinal member was removed before the bullocks were tied to the cart. The cart was then moved to the starting point marked on each terrain. The recorder was switched on just before the cart driver drove the cart over the test length of the terrain. The pens recorded the pull and bending moment $M_{l l}$ throughout the test. The recorder was switched off at the end of the test. The average velocity of the cart was determined with a stop-watch by clocking the time taken by the cart to cover the test length. The cart was then turned round for operation over the same stretch in the reverse direction. During this test also, pull and bending moment records were obtained and the average speed of the cart was also determined.

\section{Analysis of test data}

The experimental cart fitted with pneumatic wheels was run with tyre pressure of 1.4 $(20 \mathrm{psi})$ and $2 \cdot 1 \mathrm{kgf} / \mathrm{cm}^{2}$ (30 psi) on each chosen terrain both in the forward and reverse directions. The pneumatic wheels were then removed to fit the cart with conventional steel-rimmed wooden wheels. The experimental cart with conventional steel-rimmed wheels was then tested over the same terrains the pneumatic wheel cart was tested. Pull and bending moment records were obtained in all cases. A typical set of pull vs time and moment vs time records is given in figure 8 .

A study of the pull vs time records shows that the bullocks pull the cart rather discontinuously. The waviness in the pull vs time record is ascribed to the discontinuous motion of the bullocks as they walk along pulling the cart. As may be

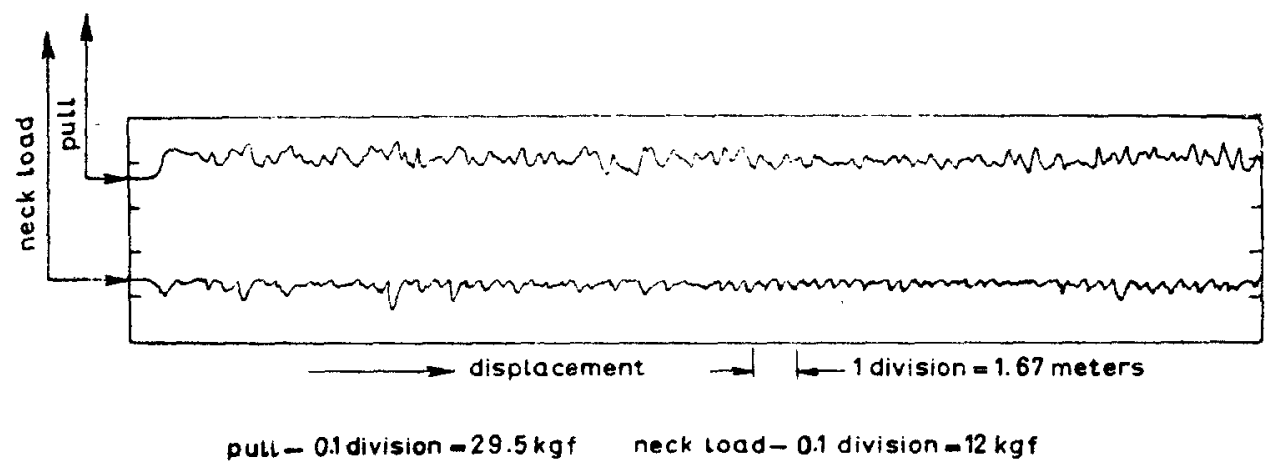

Figure 8. Typical record of pull and neck load. 
seen from equation (1c), the low frequency waviness in the bending moment vs time records is due to modulation of the bending moment $W_{R} y$ due to the neck load by the bending moment $P x$ arising from the discontinuous pull.

To facilitate measurements, all the records were magnified with the aid of an epidiascope. The heights of peaks and valleys in each record were estimated to an accuracy of $\pm 0.1 \mathrm{~mm}^{*}$.

The relatively high frequency low amplitude peaks in these records were attributed to dynamic effects arising partly from the wheel and terrain interaction and partly from the variation in the motion of the bullocks. To filter off most of these disturbances only peaks/valleys of amplitude greater than about $0.5 \mathrm{~mm}$ were measured and used in the analysis.

\subsection{Analysis of pull vs time records}

On each record, the height of the peak(s) $h_{s}$ at the start of the motion was measured from the zero load (reference) line to estimate the force required to set the cart in motion. This data is used to estimate the static effective coefficient of friction $\mu_{s}$.

The average pull is determined from

$$
\bar{P}_{d(\max )}=C_{p} \sum_{i=1}^{n} h_{p i} / n
$$

where $h_{p 1}, h_{p 2} \ldots h_{p i} \ldots h_{p n}$ are the amplitudes of the peaks in $\mathrm{mm}$ in the pull vs time record, $n$ is the number of peaks (peak(s) $h_{s}$ are omitted from this analysis), and $C_{p}$ is the calibration constant in $\mathrm{kg} / \mathrm{mm}$. This data is used to estimate the mean dynamic effective coefficient of friction $\bar{\mu}_{d}$.

From the heights of the valleys $h_{v}$ in the pull vs time record, the average minimum pull is estimated

$$
\widetilde{P}_{d(\min )}=C_{p} \sum_{i=1}^{n} h_{v i} / n=\sum_{i=1}^{n} P_{d i(\min )} / n
$$

The mean amplitude of fluctuation in the pull is calculated from:

$$
\overline{\boldsymbol{P}}_{d a}=\overline{\boldsymbol{P}}_{d(\max )}-\overline{\boldsymbol{P}}_{d(\min )}
$$

\subsection{Analysis of bending moment vs time records}

As the bending moment due to the pull acts in a direction opposite to the bending moment due to the upward neck load, a peak in the pull vs time record should correspond to a valley in the bending moment vs time record and vice versa.

From equation (2) the mean neck load $\bar{W}_{R p}$ can be determined

$$
\bar{W}_{R F}=\sum_{i=1}^{n} W_{R p i} / n,=\left(C_{n} \sum_{i=1}^{n} h_{p i}^{\prime} / n\right)+P_{d(\min )} \frac{x}{y}
$$

-For checking the accuracy of measurement with the epidiascope, some records were analysed more accurately with a travelling microscope. This check showed that the error in analysis based on epidiascope measurements was less than $5 \%$. 
where $h_{p i}^{\prime}$ are the heights of peaks in the bending moment vs time record $C_{n}$ is the calibration constant for conversion of moment data, $h_{p i}^{\prime}$ in $\mathrm{mm}$ of pen deflection to equivalent vertical load or neck load on the bullocks.

The mean neck load $\bar{W}_{R v}$ is given by

$$
\bar{W}_{R v}=\sum_{i=1}^{n} W_{R v i} / n=\left(C_{n} \sum_{i=1}^{n} h_{p i}^{\prime} / n\right)+\bar{P}_{d(\max )} \frac{x}{y}
$$

where $h_{v i}^{\prime}$ are the heights of valleys in the bending moment vs time record and $n$ is the number of valleys used in the computation.

Also, $\quad \bar{W}_{R a}=\bar{W}_{R P}-\bar{W}_{R v}$,

where $\bar{W}_{R a}$ is the mean amplitude of the fluctuation in the neck load.

\subsection{Estimation of coefficients of friction}

For eliminating the error due to gradient variations in the terrain in the estimation of $\bar{\mu}_{d}$, the experimental cart was run in both forward and return directions on the same terrain. If $\boldsymbol{P}_{d i(\max )}$ and $\boldsymbol{P}_{d i(\max )}^{\prime}$ are the pull required to negotiate in the forward and return directions respectively on the $i$ th elemental length of the terrain of gradient $\theta$, then from equation (11) of Part 1 (Raghavan \& Nagendra 1979)

$$
\begin{aligned}
& P_{d i(\max )} / W_{L}=\mu_{d}\left(\cos \theta-\left(W_{R v i}\right) / W_{L}\right)+\sin \theta, \\
& P_{d i(\max )}^{\prime} / W_{L}=\mu_{d}\left(\cos \theta-\left(W_{R v i}^{\prime}\right) / W_{L}\right)-\sin \theta,
\end{aligned}
$$

where $W_{R v i}$ and $W_{R v i}^{\prime}$ are the corresponding neck loads in the forward and return directions respectively. (As the cart velocities are quite low, the acceleration $a_{c}$ is neglected). Hence

$$
\left[P_{d i(\max )}+P_{d i(\max )}^{\prime}\right] / 2 W_{L}=\mu_{d}\left\{\cos \theta-\left[\left(W_{R v i}+W_{R v i}^{\prime}\right) / 2 W_{L}\right]\right\} .
$$

As for gradients less than 1 in 5 , the error due to replacing $\cos \theta$ by 1 is less than $2 \%$ equation (10) is simplified:

$$
\left[P_{d i(\max )}+P_{d i(\max )}^{\prime}\right] / 2 W_{L}=\mu_{d i}\left\{1-\left[\left(W_{R v i}+W_{R v i}^{\prime}\right) / 2 W_{L}\right]\right\}
$$

If there are $n$ such elemental lengths in the test length, the mean dynamic effective coefficient of friction is given by

$$
\begin{aligned}
\bar{\mu}_{d}= & \left\{\sum_{i=1}^{n} 0.5\left[P_{d i(\max )}+P_{d i(\max )}^{\prime}\right]\right\} / n W_{L}\left[1-\sum_{i=1}^{n}\left(W_{R v i}\right.\right. \\
& \left.\left.+W_{R v i}^{\prime}\right) / 2 n W_{L}\right], \\
= & 0.5\left[\bar{P}_{d f(\max )}+\bar{P}_{d r(\max )}\right] / W_{L}\left[1-\left(\bar{W}_{R v f}+\bar{W}_{R v r}\right) / 2 W_{L}\right]
\end{aligned}
$$

where $\bar{P}_{d f(\max )}$ and $\bar{P}_{d r(\max )}$ are the mean values of pull, $\bar{P}_{d(\max )}$ (see equation (3)) in the forward and return run respectively, $\bar{W}_{R v f}$, and $\bar{W}_{R v r}$ are the corresponding mean 
values for the neck load $\bar{W}_{R v}$ (see equation (7)) for forward and reverse runs respectively. Similarly the mean static effective coefficient of friction is given by

$$
\bar{\mu}_{s}=0.5\left(\bar{P}_{s s}+\bar{P}_{s r}\right) / W_{L}\left\{1-\left[\left(\bar{W}_{R s}+\bar{W}_{R s r}\right) / 2 W_{L}\right]\right\},
$$

where $\bar{P}_{s f}$ and $\bar{P}_{s r}$ are the mean peak load at the start of the motion of the cart in the forward and reverse runs respectively. $\bar{W}_{R s f}$ and $\bar{W}_{R s r}$ are the corresponding neck loads in the forward and reverse runs respectively.

\section{Discussion of test results}

Test records obtained under various operating conditions for carts fitted with pneumatic and steel-rimmed wooden wheels were analysed as described above. The results of these analyses are presented in tables 3 and 4.

The average speed of the cart was in the range of 3 to $4 \mathrm{~km} / \mathrm{hr}$. The total weight $W_{L}$ of the cart fitted with pneumatic and steel-rimmed wooden wheels were $830 \mathrm{kgf}$ $(1830 \mathrm{lb})$ and $932.5 \mathrm{kgf}(2056 \mathrm{lb})$ respectively. The height $h$ of the neck of the bullocks was $100 \mathrm{~cm}(40 \mathrm{in}$.$) .$

\subsection{Pull vs time records}

In the case of the cart fitted with pneumatic wheels, the mean static effective coefficient of friction $\bar{\mu}_{s}$ was about $\mathbf{0 . 2 5}$ on a tar road. On the mud road and the grassy terrain, it was higher and in the range of 0.265 to 0.315 . On the tar road, the variation of tyre pressure from $1.4(20 \mathrm{psig})$ to $2.1(30 \mathrm{psig}) \mathrm{kgf} / \mathrm{cm}^{2}$ had no significant effect on $\bar{\mu}_{s}$. However, on the mud road and on the grassy terrain, this increase in tyre pressure caused a significant increase-from 0.265 to 0.315 -in $\bar{\mu}_{s}$. Also at both the tyre pressures, $\bar{\mu}_{s}$ was essentially the same for both the mud road and the grassy terrain.

In the case of cart fitted with steel-rimmed wooden wheels, $\bar{\mu}_{s}$ on the tar road was somewhat lower than on the mud road. It was highest on the grassy terrain.

A comparative study (table 5) indicates that $\bar{\mu}_{\mathrm{s}}$ for the cart with steel-rimmed wooden wheels is significantly higher than $\bar{\mu}_{s}$ for the cart with pneumatic wheels. It is $16 \%$ and $24 \%$ higher on the tar road and the grassy terrain respectively. However, on the mud road, $\bar{\mu}_{s}$ for the former cart is only slightly higher.

The mean dynamic effective coefficient of friction $\bar{\mu}_{d}$ for the cart fitted with pneumatic wheels was about the same $(\sim 0.08)$ on the tar road and the mud road. However, on the grassy terrain, it was higher and in the range 0.16 and 0.20 . On the tar road and the mud road, tyre pressure variation from 2.1 (30 psig) to $1.4(20 \mathrm{psig}) \mathrm{kgf} /$ $\mathrm{cm}^{2}$ had no significant effect on $\bar{\mu}_{d}$. On the grassy terrain the same decrease in tyre pressure resulted in a significant $(25 \%)$ decrease in $\bar{\mu}_{\alpha}$.

In the case of the cart fitted with steel-rimmed wooden wheels $\bar{\mu}_{d}$ on the mud road and the grassy terrain were about $45 \%$ and $125 \%$ respectively higher than that on the tar road. A comparative study of $\bar{\mu}_{d}$ for the carts with steel-rimmed wooden wheels and pneumatic wheels indicates that the $\bar{\mu}_{d}$ for the former cart is $27 \%$ and $31 \%$ lower on the tar road and the grassy terrain respectively. On the mud road, however, $\bar{\mu}_{d}$ for the cart with steel-rimmed wooden wheels is only slightly higher. 


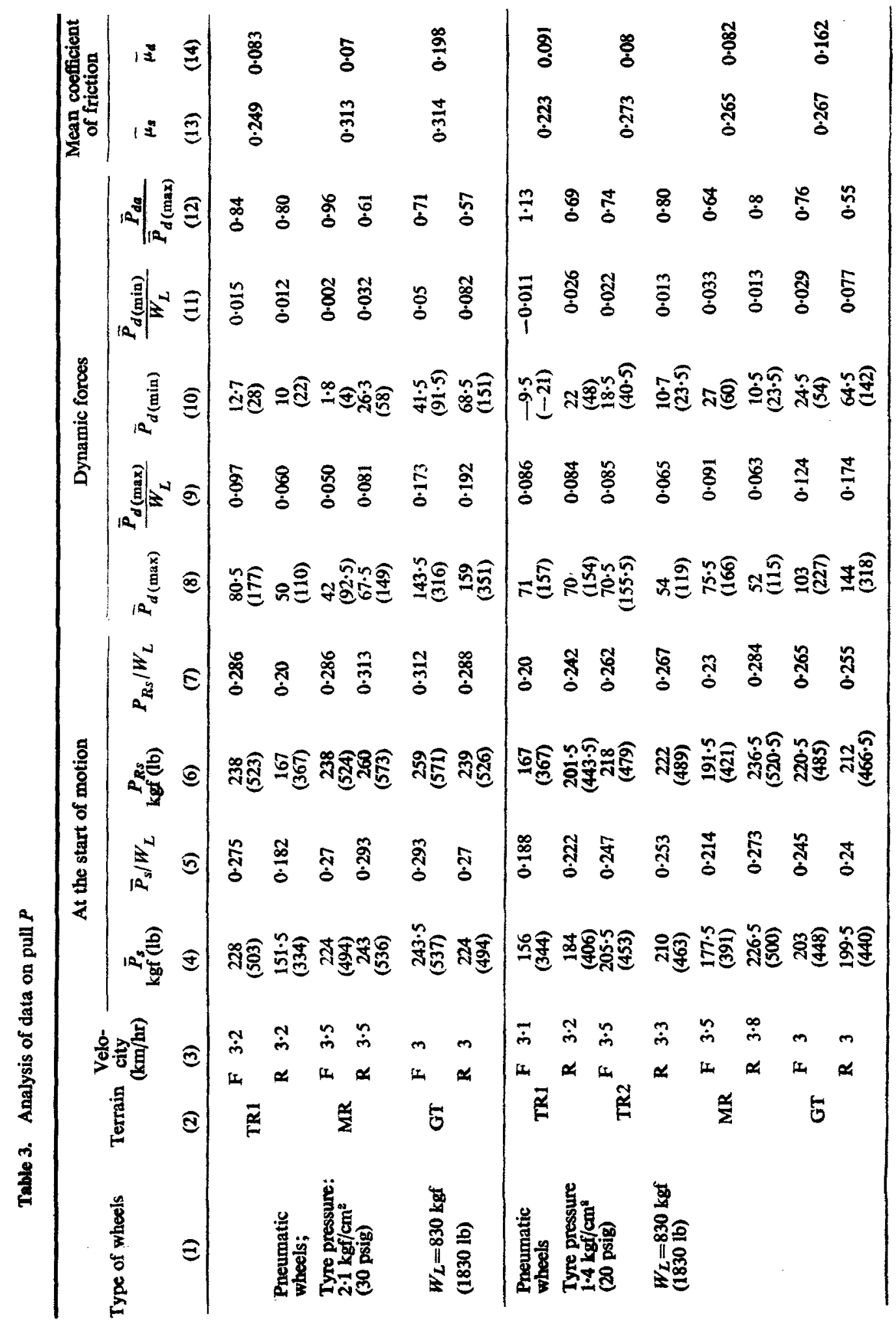




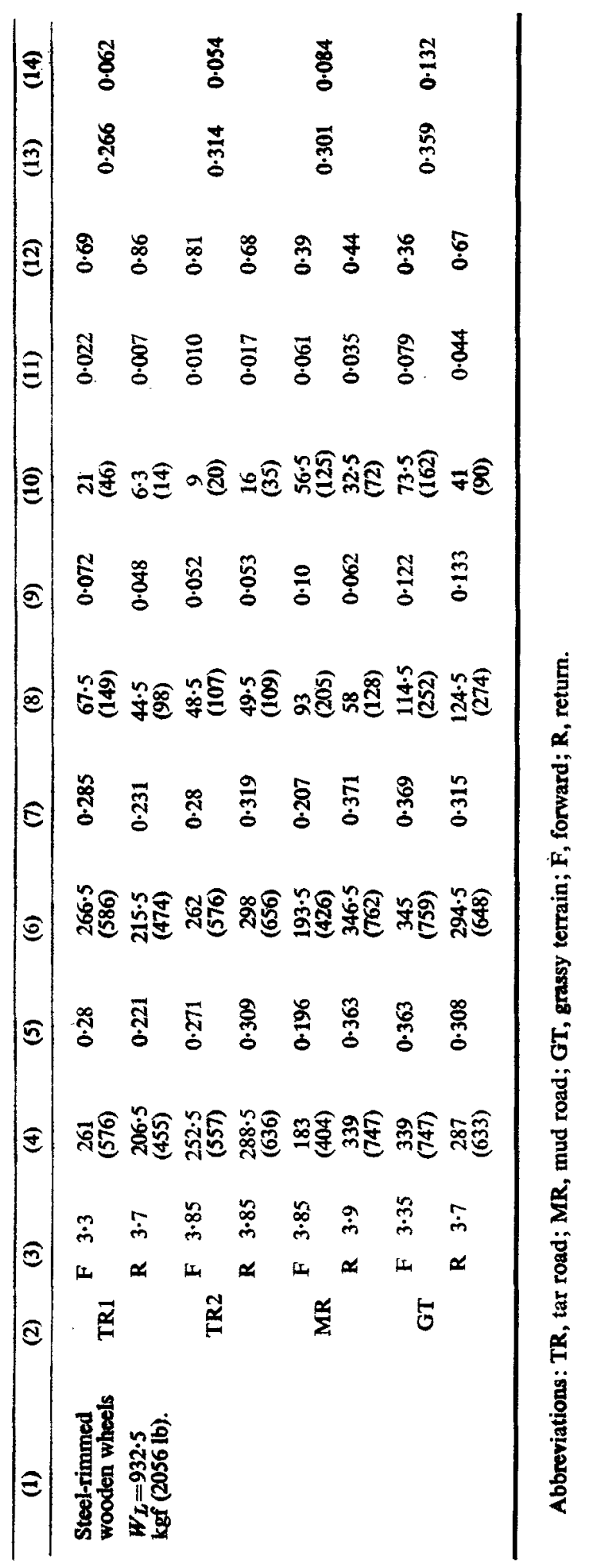




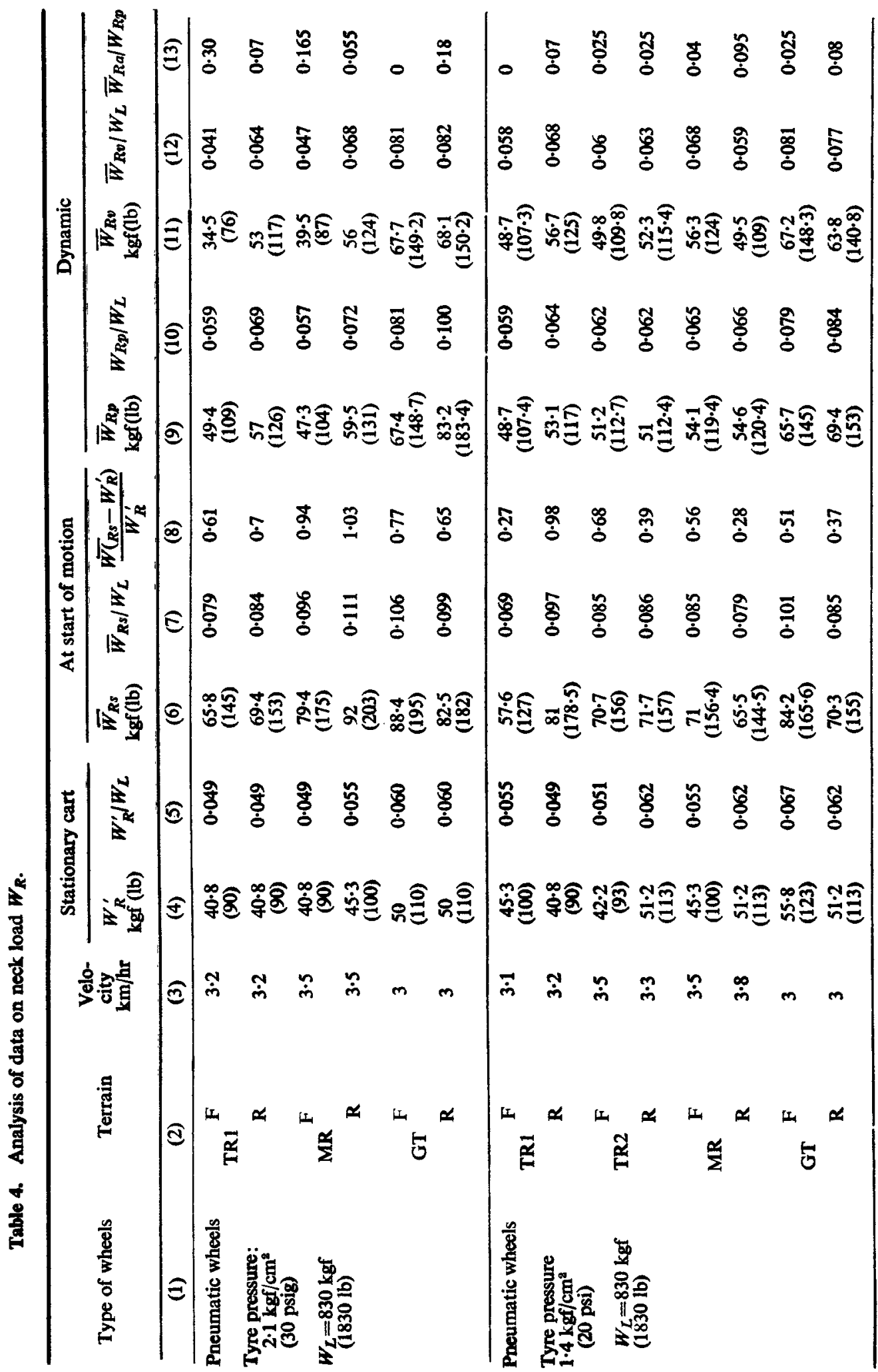




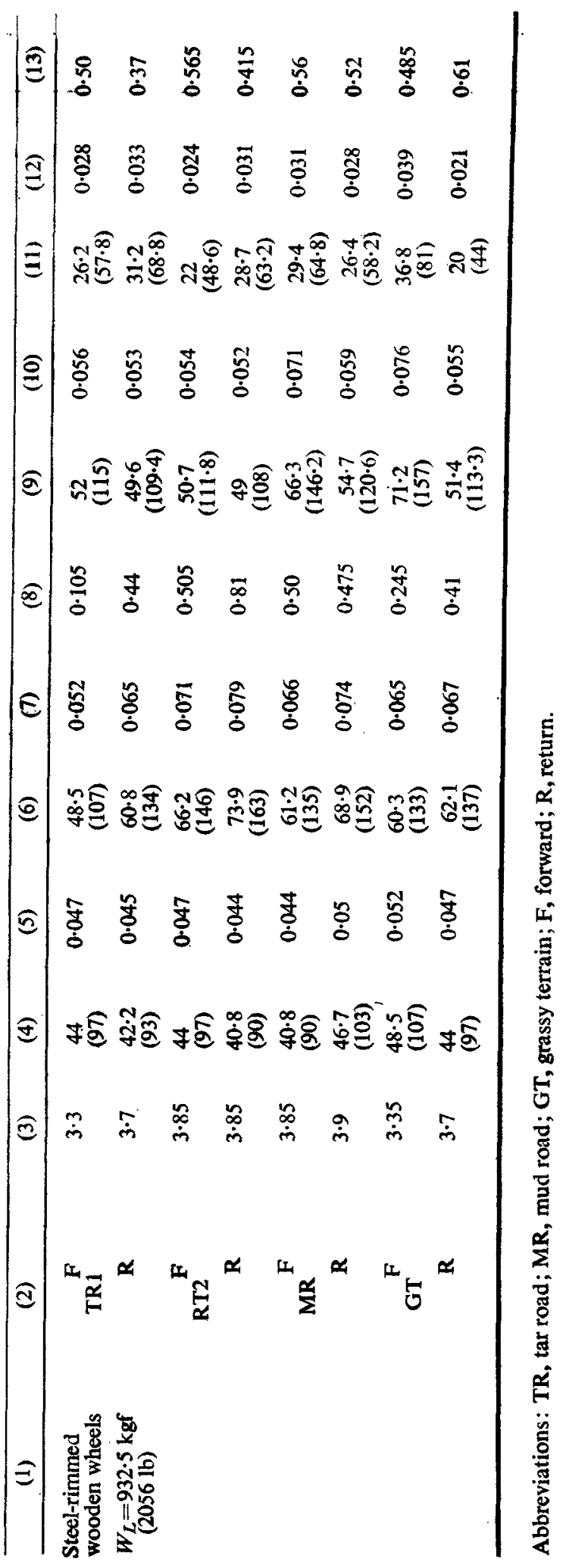

Pro. C-4 
Table 5. $\bar{\nu}_{s}$ and $\bar{\mu}_{d}$ for bullock carts with pneumatic wheels and with steel-rimmed wooden wheels.

\begin{tabular}{|c|c|c|c|c|c|c|c|c|}
\hline \multirow{3}{*}{ Terrain } & \multicolumn{4}{|c|}{$\begin{array}{l}\text { Cart with pneumatic } \\
\text { wheels }\end{array}$} & \multicolumn{4}{|c|}{$\begin{array}{l}\text { Cart with steel-rimmed } \\
\text { wooden wheels }\end{array}$} \\
\hline & \multicolumn{2}{|c|}{$\bar{\mu}_{s}$} & \multicolumn{2}{|c|}{$\bar{\mu}_{d}$} & \multicolumn{2}{|c|}{$\bar{\mu}_{s}$} & \multicolumn{2}{|c|}{$\overline{\mu_{d}}$} \\
\hline & Range & $\begin{array}{l}\text { Mean } \\
\text { value }\end{array}$ & Range & $\begin{array}{l}\text { Mean } \\
\text { value }\end{array}$ & Range & $\begin{array}{l}\text { Mean } \\
\text { value }\end{array}$ & Range & $\begin{array}{l}\text { Mean } \\
\text { value }\end{array}$ \\
\hline Tar road & $\begin{array}{l}0.22- \\
0.27\end{array}$ & 0.25 & $\begin{array}{l}0.08- \\
0.09\end{array}$ & 0.085 & $\begin{array}{l}0.26- \\
0.31\end{array}$ & 0.29 & $\begin{array}{l}0.05 \\
0.06\end{array}$ & 0.058 \\
\hline Mud road & $\begin{array}{l}0.265- \\
0.315\end{array}$ & 0.29 & $\begin{array}{l}0.07- \\
0.08\end{array}$ & 0.075 & - & $0 \cdot 30$ & - & 0.084 \\
\hline Grassy terrain & $\begin{array}{l}0.265- \\
0.315\end{array}$ & 0.29 & $\begin{array}{l}0.16- \\
0.20\end{array}$ & $0 \cdot 18$ & - & 0.36 & - & 0.132 \\
\hline
\end{tabular}

For both types of carts, the mean amplitude of fluctuation of the pull $\overline{\boldsymbol{P}}_{d a}$ on a tar road is in the range of 68 to $85 \%$ of the $\bar{P}_{d(\max )}$. However, on the mud road and the grassy terrain, $\bar{P}_{d a}$ for the cart with steel-rimmed wooden wheels is significantly lower.

\subsection{Neck load}

In all these tests, the neck load $W_{R}^{\prime}$ on the stationary bullocks (just before they start moving the cart) was set at a value in the range of 40 to $56 \mathrm{~kg}$. At the start of the motion of the cart due to the force exerted by the bullocks the neck load increased considerably. This increase in the neck load i.e., $\left(\bar{W}_{R S}-W_{R}^{\prime}\right) / W_{R}^{\prime}$ at the start of the motion in the case of the cart with pneumatic smaller wheels was higher; the mean value was 0.62 . The corresponding value for the cart with larger diameter steel-rimmed wooden wheels was 0.44 .

The increase in the mean neck load $\left(\bar{W}_{R p}-W_{r}^{\prime}\right)$ in the moving cart was maximum on the grassy terrain. On the tar road and the mud road, the increase in the mean neck load $\left(\bar{W}_{R p}-W_{R}^{\prime}\right)$ was about the same for both types of carts. The mean amplitude of fluctuation in the neck load $\left(\bar{W}_{R a} / \bar{W}_{R p}\right)$ was the lowest in the cart with pneumatic wheels inflated to a pressure of $1.4 \mathrm{kgf} / \mathrm{cm}^{2}(20 \mathrm{psig})$; it was less than $0 \cdot 1$. An increase in tyre stiffness due to increase in pressure from 1.4 to $2.1 \mathrm{kgf} / \mathrm{cm}^{2}$ resulted in a higher $\bar{W}_{R a} \bar{W}_{R p}$. It was the highest for the cart fitted with stiff steel-rimmed wooden wheels and was in the range 0.37 to 0.61 .

It was also observed that the bullocks were subjected to a ground-induced vibratory neck load of low amplitude but of a relatively higher frequency. The ground-induced vibrating load content was significantly higher in the case of the cart fitted with steelrimmed wooden wheels.

\section{Conclusions}

A strain-gauge load cell with separate bridges for measurement of the pull and the bending moment in the plane containing the net neck load and pull, was developed and fixed in the longitudinal member of an experimental cart at a section about $30 \mathrm{~cm}$ 
from the yoke end. The outputs from these bridges were connected to a Kelvin and Hughes pen recorder through separate strain meters and amplifiers. Both the pull and moment measuring systems were finally calibrated in situ. A cart fitted first with pneumatic wheels and then with steel-rimmed wooden wheels was tested on three types of terrains - tar road, mud road, and grassy terrain. Pull vs time and moment vs time records were obtained in each test and analysed using the procedure developed.

The analysis of all the test records reveal:

(i) The bullocks pull the cart rather discontinuously at the low veocities (3 to 4 $\mathrm{km} / \mathrm{hr}$ ) at which these carts normally operate. For both types of carts-carts fitted with either pneumatic wheels or steel-rimmed wooden wheels-on the tar road, the mean amplitudes of fluctuation of the pull $\bar{P}_{d a}$ is in the range of 68 to $85 \%$ of the average pull $\bar{P}_{d(\max )}$. However, on the mud road and the grassy terrain $\bar{P}_{d a}$ for the cart with steel-rimmed wooden wheels is significantly lower.

(ii) On the tar road and the grassy terrain, the mean static coefficient of friction for the cart with steel-rimmed wooden wheels is significantly higher than for the cart with pneumatic wheels. On the mud road however $\bar{\mu}_{s}$ for the former cart is only slightly higher.

(iii) The mean dynamic coefficient of friction for the cart with steel-rimmed wooden wheels is 27 and $31 \%$ lower on the tar road and grassy terrain respectively. On the dry hard mud road, however, $\vec{\mu}_{d}$ of the cart with steel-rimmed wooden wheels is only slightly higher than for the cart with pneumatic wheels.

These results show that the dynamic frictional resistance of the terrain $\left(\vec{\mu}_{d}\right)$ for the cart fitted with steel-rimmed wooden wheels is lower than for the cart with pneumatic wheels so long the wheels do not dig or sink into the terrain. On a dry hard mud road, $\vec{\mu}_{d}$ for both types of carts are comparable chiefly due to the increased deformation of the terrain in the case of cart with steel-rimmed wooden wheels. Increase in the width of the wheels would minimise the deformation of the terrain.

(iv) The increase in the neck load on the bullocks was maximum at the start of motion of the cart. Also this increase in the neck load was higher for the cart with pneumatic smaller wheels.

The average increase in the neck load while the cart is in motion was maximum on the grassy terrain. On the tar road and the mud road however this increase in the neck load was about the same for both types of carts.

(v) The mean amplitude of fluctuation in the neck load, $\bar{W}_{R a}$ was the lowest in the case of cart fitted with pneumatic wheels having a tyre pressure of $1.4 \mathrm{kgf} / \mathrm{cm}^{2} . \quad \bar{W}_{R a}$ was the highest for the cart fitted with the relatively stiff steel-rimmed wooden wheels.

The ground-induced low-amplitude high-frequency vibratory load content in the neck load was also large in the case of cart fitted with the steel-rimmed wooden wheels. Thus, due to inherent damping, the discomfort caused to the bullocks due to neck load fluctuations is significantly less in the case of cart fitted with pneumatic wheels.

(vi) The experimental results indicate that there is a need to develop an alternative wear-resistant material for the rim of the wooden wheels, which has built-in damping and a stiffness considerably lower than that of steel, e.g., a rubber composite. 
The work reported here was carried out under a project sponsored by the Tata Energy Research Institute, Bombay. The authors gratefully acknowledge the encouragement and help received from Prof. A K N Reddy of Indian Institute of Science, Bangalore. The authors are grateful to Mr P V Reddy, for his enthusiastic and valuable assistance in the development of the load cell and in the experiments on the cart; to Mr P R Arora for his assistance in the calibration of the load cell; to Mr K R Hariharan, Mr H S Sathyanarayana and Mr. H R A Iyengar, Mr V S Anthony and Mr Muniswamy for their untiring help in conducting the experiments on the cart; to Mr P Srikanth and Mr T S Shanker, M.E.Course students of the Department of Mechanical Engineering, Indian Institute of Science for their assistance in the load cell design ; to Mr C Shankaranarayana Rao for his assistance in preparing the figures; to $\mathrm{Mr}$ S Narayana Das for his assistance in photography. Help given by the M E Workshop staff in the fabrication of the load cell is gratefully acknowledged.

\section{List of symbols}

$a_{c} \quad$ acceleration of cart in the direction of motion $\left(\mathrm{cm} / \mathrm{s}^{2}\right)$

$C_{n} \quad$ calibration constant to convert moment data in $\mathrm{mm}$ of pen deflection to equivalent neck load ( $\mathrm{kgf} / \mathrm{mm})$

$C_{p} \quad$ calibration constant to convert pull data in $\mathrm{mm}$ of pen defiection to corresponding pull $(\mathrm{kgf} / \mathrm{mm})$

$h \quad$ amplitude in pull vs time record (mm)

$h^{\prime} \quad$ amplitude in moment $M_{l l}$ vs time record (mm)

$M_{l l} \quad$ bending moment about axis $l l$ (figure 1)

$M_{n n} \quad$ bending moment about axis $n n$ (figure 1)

$n \quad$ number of values or events

$P \quad$ pull exerted by the bullocks on the cart (kgf)

$\boldsymbol{P}_{d i(\max )}$ magnitude of $i$ th peak in $\mathrm{kgf}$ in the pull vs time record (kgf)

$P_{d i(\min )}$ magnitude of $i$ th valley in $\mathrm{kgf}$ in the pull vs time record (kgf)

$\bar{P}_{d(\max )}$ average maximum pull (kgf)

$\bar{P}_{d(\min )}$ average minimum pull (kgf)

$\bar{P}_{d a} \quad$ mean amplitude of fluctuation in pull

$P_{R} \quad\left(P^{3}+W_{R}^{2}\right)^{1 / 2}:$ resultant force exerted by the bullocks on the yoke

$T$ torque on the load cell $(\mathrm{kgf} / \mathrm{cm})$ (figure 1$)$

$W_{L} \quad$ total load on the cart (kgf)

$W_{R} \quad$ neck load on the bullocks (kgf)

$\bar{W}_{R v} \quad$ average neck load corresponding to peaks in the moment vs time record (kgf)

$\bar{W}_{R^{n}}$ average neck load corresponding to valleys in the moment vs time record (kgf)

$\bar{W}_{R a} \quad$ mean amplitude of fluctuation in the neck load

$\theta$ slope of the terrain (degree)

$\bar{\mu}_{d} \quad$ mean dynamic effective coefficient of friction

$\bar{\mu}_{i} \quad$ mean static effective coefficient of friction

$\mu \epsilon \quad$ microstrain 
Subscripts

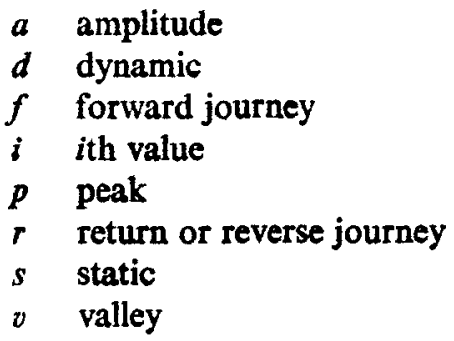

\section{References}

Anon 1977 Modernisation of bullock cart (Bangalore: Indian Institute of Management) Marks L S (ed.) 1951 Mechanical engineers handbook (New York: McGraw Hill)

Vagh B V 1944-45 J. Indian Roads Congr. $9(2) 55,9(3) 49$

Vagh B V 1947-48 J. Indian Roads Congr. 12(4) 5, 12 (5) 375

Vagh B V 1948-49 J. Indian Roads Congr. 13 (2) 181, 13 (4) 158

Vagh B V 1950-51 J. Indian Roads Congr. 15 (1) 65, 15 (2) 237, 15 (4) 629

Raghavan M R \& Nagendra H R 1979 Proc. Indian Acad. Sci. C2 435 
Plate 1

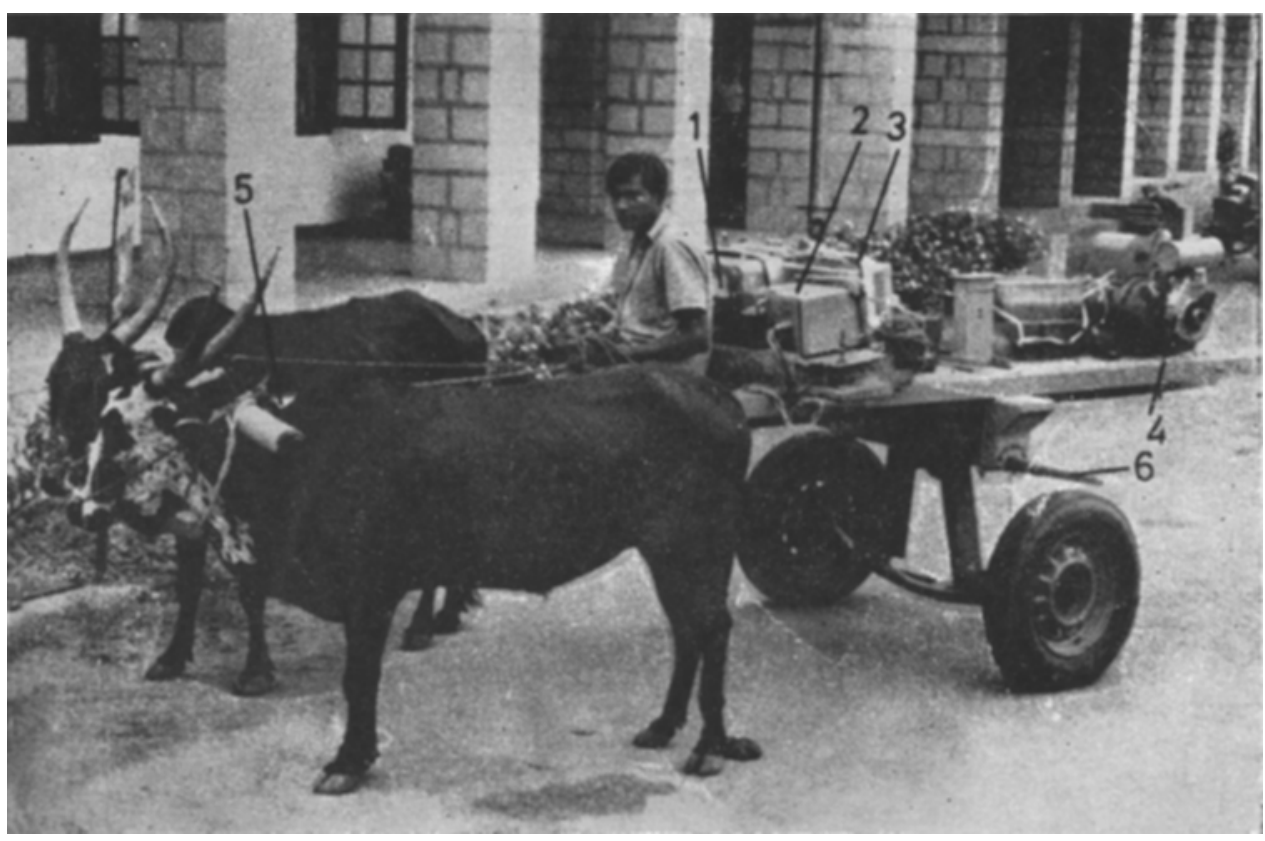

Figure 5. Experimental bullock cart. 1. Strain meter. 2. Kelvin and Hughes recorder. 3. Preamplifier. 4. Engine generator set. 5. Load cell. 6. Axle for steelrimmed wooden wheels. 